\title{
Medical Co Morbidities in Patients of Frontal Temporal Dementia -A Hospital Based Study
}

\author{
Manjunadh Muralleedharan ${ }^{1 *}$, Junaid Nabi ${ }^{1}$ and Mohammad Sarwar Mir ${ }^{2}$ \\ ${ }^{1}$ Department of Geriatric Mental health, India \\ ${ }^{2}$ Department of Hospital Administration, SKIMS, India
}

*Corresponding author: Manjunadh Muralleedharan, DM Resident, Department of Geriatric Mental health, India

Submission: 眥 August 18, 2017; Published: 眥 October 30, 2017

\begin{abstract}
Dementia is increasingly becoming a major healthcare challenge as the population ages worldwide, with an estimated 25 million cases of dementia globally. The most common cause of dementia is Alzheimer's disease (AD) which affects approximately 5.4 million individuals in the United States alone. Following the identification of tau gene mutations in familial forms of this disorder, there is increasing interest in genetic factors that may predispose to the disease. About $60 \%$ of patients with frontotemporal dementia have no family history of dementia and are considered to be sporadic cases. Genetic factors, such as apolipoprotein E genotype and the H1 haplotype of the tau gene, have been inconsistently associated with the sporadic form of the disease. Frontotemporal dementia (FTD) includes most of these conditions, and is characterized by specific behavioral changes, frontotemporal atrophy on CT or MRI, and the absence of senile plaques and neurofibrillary tangles at postmortem examination. In view of paucity of studies in the said condition, we decided to work on this. This study was designed to find out medical co morbidities in patients of front temporal dementia.
\end{abstract}

Methods: Thirty successive patients diagnosed as FTD who fulfilled inclusion and exclusion criteria were taken up for the study and administered the Clinical Global Impression scale to find out severity of the disorder. Each patient was informed about the purpose of interview; his/her consent was obtained and strict confidentiality was ensured.

Result: Out of hundred cases of amputation, 8 patients had moderate symptoms followed by 15 patients with marked symptoms and remaining 7 patients have severe symptoms. The total sample size of 30 patients, 10 patients had single co morbidity, while as 10 is having two co morbidities and 5 patients had three co morbidities. Rest 5 patients didn't have any medical co morbidity.

Discussion: In our study, the most common psychiatric co-morbidity was Major Depressive Disorder (53\%) followed by with Generalized Anxiety Disorder in 15\% and Panic Disorder in 9\%.

Keywords: Fronto temporal dementia; Co Morbidity; Medical related problems

\section{Introduction}

Dementia is increasingly becoming a major healthcare challenge as the population ages worldwide, with an estimated 25 million cases of dementia globally [1]. The most common cause of dementia is Alzheimer's disease (AD) which affects approximately 5.4 million individuals in the United States alone [2]. Frontotemporal dementia is a neurodegenerative disorder with a predominantly presenile onset of behavioural changes and cognitive decline [3]. Following the identification of tau gene mutations in familial forms of this disorder, there is increasing interest in genetic factors that may predispose to the disease. About $60 \%$ of patients with frontotemporal dementia have no family history of dementia and are considered to be sporadic cases. Genetic factors, such as apolipoprotein E genotype and the H1 haplotype of the tau gene, have been inconsistently associated with the sporadic form of the disease [4,5]. Frontotemporal dementia (FTD) includes most of these conditions, and is characterized by specific behavioral changes, frontotemporal atrophy on CT or MRI, and the absence of senile plaques and neurofibrillary tangles at postmortem examination. In view of paucity of studies in the said condition, we decided to work on this. This study was designed to find out medical co morbidities in patients of fronto temporal dementia.

\section{Aims \& Objectives}

A. To find out the socio-demographic details of patients of Fronto Temporal Dementia

B. To study medical co morbidities and severity in patients of Fronto Temporal Dementia by using clinical global impression severity scale (CGISS).

\section{Materials and Methods}

This was a cross sectional, observational study conducted in the department of geriatric mental health, a tertiary care teaching hospital. King George Medical University is one of the oldest institutes of India. It is located in the centre of Lucknow which is the capital of Uttar Pradesh. It has a wide catchment area. The 
sample size included 30 patients. The study included patients who were diagnosed with fronto temporal dementia with help of nearby Criteria. These are the most widely used criteria for the diagnosis of frontotemporal dementia (FTD) in practice and research. These criteria emphasise 3 clinical syndromes, characterized in turn by disorder of personality, social cognition and social conduct, progressive aphasia, or progressive associative agnosia [6]. Within these 3 categories, symptoms defining the syndrome are specified. Thus insidious decline in social and personal conduct, emotionality, and insight characterize the frontal dementia syndrome; agrammatism, anomia, vacuous speech, and paraphasias, in some combination, characterize the aphasia syndrome; and loss of face or object recognition the agnosia syndrome. The diagnosis is excluded by abrupt onset or evidence of cerebrovascular injury.

\section{Research Instrument}

a. Study case record/proforma

A. It consisted of a self-designed interview schedule to record the socio-demographic data, the psychiatric history including that of the suicide attempt, mode of suicide, causes/ factors, the physical examination and International Personality Disorder Examination mental status examination.

B. Co morbidity assessment was done by detailed medical evaluation and evaluating past record.

\section{b. Clinical global impression}

The CGI, developed by National Institute of Mental Health (NIMH), is a three-item scale which measures overall illness severity. Repeated, it can evaluate response to treatment. The rater evaluates the severity of the patient's illness based on his total experience with the specific patient population to which the patient belongs. It has three parts: severity of illness (CGI-S), global improvement (CGI-I) and efficacy index. Severity of illness is rated on a seven-point spectrum (1=normal, $7=$ among the most extremely ill patients) [7].

\section{c. Statistics}

Data obtained was then entered in Microsoft excel and analyzed in Statistical Package for the Social Sciences (SPSS. version 17) for descriptive statistics.

\section{Results}

(Table 1-3), (Figure 1 \& 2)

Table 1: Summarizes the characteristic and socio-demographic details of the participants.

\begin{tabular}{|c|c|c|}
\hline \multicolumn{2}{|c|}{ Characteristics } & Value \\
\hline Total sample size & & 30 \\
\hline \multirow{2}{*}{ Age (years) } & $50-65$ & 23 \\
\cline { 2 - 3 } & $66-80$ & 7 \\
\hline \multirow{2}{*}{ Gender } & Male & 18 \\
\cline { 2 - 3 } & Female & 12 \\
\hline \multirow{2}{*}{ Resident } & Rural & 21 \\
\cline { 2 - 3 } & Urban & 9 \\
\hline
\end{tabular}

Table 2: Medical co morbidities.

\begin{tabular}{|c|c|}
\hline $\begin{array}{c}\text { Medical Co- } \\
\text { Morbidity }\end{array}$ & Distribution \\
\hline DM & 8 \\
\hline HTN & 13 \\
\hline Hypothyriodism & 9 \\
\hline Migraine & 5 \\
\hline $\begin{array}{c}\text { Connective Tissue } \\
\text { Disorder }\end{array}$ & 2 \\
\hline BPH & 8 \\
\hline
\end{tabular}

Table 3: CGI (Clinical Global Impression Severity) scale.

\begin{tabular}{|c|c|}
\hline $\begin{array}{c}\text { Severity of } \\
\text { illness }\end{array}$ & Distribution \\
\hline Normal & 0 \\
\hline Borderline & 0 \\
\hline Mild & 0 \\
\hline Moderate & 8 \\
\hline Marked & 15 \\
\hline Severe & 7 \\
\hline
\end{tabular}

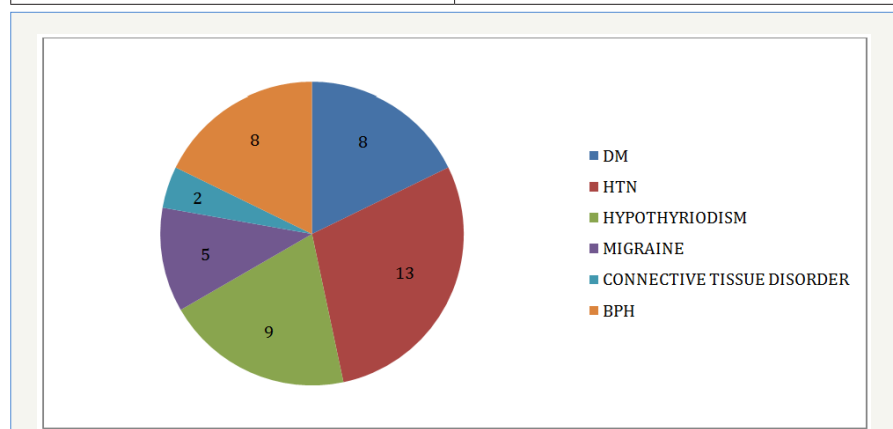

Figure 1: The total sample size of 30 patients, 10 patients had single co morbidity, while as 10 is having two co morbidities and 5 patients had three co morbidities. Rest 5 patients didn't have any medical co morbidity.

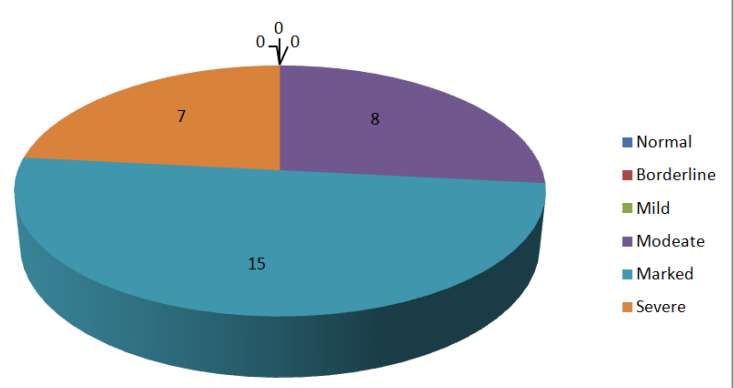

Figure 2: CGI (Clinical Global Impression Severity) scale.

\section{Discussion}

In this study an attempt has been made to study different types of medical morbidity in patients of FTD who came to department of geriatric mental illness in a tertiary care hospital in Lucknow. The significant finding of our study is to find out the prevalence of medical morbidity in patients of Fronto Temporal Dementia (FTD). 
Out of thirty cases of FTD, 23 patients were in the age group of 50 to 65 and remaining 7 were in age group of 66 to 80 . This finding is in concordance with the findings based on 17 patients with clinically diagnosed FTD in the Cambridge area of the UK, reported a prevalence of 15 cases per 100000 in people age 45-64 years.34 A study from the Netherlands of 245 patients with FTD in the Zuid-Holland province (the Netherlands), reported much lower prevalence: 3.6 per 100000 at age 50-59 years, rising to 9.4 per 100000 at age 60-69 years, and falling to 3.8 per 100000 at age 70-79 years [8]. In our study, males out numbered females by quite a bit. In sample of 30 patients, males were 18 followed by 12 females. Our finding was in contrary to few studies from west in which out of total of 245 patients from the Netherlands indicated an equal distribution of FTD among men and women (49\% men, $51 \%$ women), similar to findings in the Manchester series of 210 patients (50\% men, $50 \%$ women) $[9,10]$. Out of thirty patients, 21 belonged to rural and remaining 9 were from urban area o Lucknow and surrounding areas. This can be explained by taking into account the patient profile which visits our hospital. Since the facilities provided in our hospital are free, people from rural areas prefer to come here to seek treatment and also urban people from well to do family like to get treated from a private setup.

The total sample size of 30 patients, 10 patients had single co morbidity, while as 10 is having two co morbidities and 5 patients had three co morbidities. Rest 5 patients didn't have any medical co morbidity. Hypertension was found in total of 13 patients followed by hypothyroidism in 9 patients. Diabetes mellitus and Benign prostrate hypertrophy was seen in 8 patients each. This finding is similar to what picture we see in Alzheimer's Dementia. On the CGI (Clinical Global Impression Severity) scale, majority (50\%) were in the marked severity range. None of the patients were normal borderline or mild as per scale scoring.

\section{Conclusion}

In this study we found that FTD was more common in middle age group. Males outnumbered females with 18 patients out of total
30 patients. HTN was the major medical co morbidity found in the patients.

Findings of this study also indicated a strong relationship between places the patient resides with the type of medical comorbidity. Thus the above factors would have to be focused upon, in the management, and, during the counseling sessions of care takers of patients of FTD.

\section{References}

1. Wimo A, Winblad B, Torres AH, Strauss VE (2003) The magnitude of dementia occurrence in the world. Alzheimer Dis Assoc Disord 17(2): 63-67.

2. Alzheimer's Association (2012) Alzheimer's disease facts and figures. Alzheimers Dement 8(2): 131-168.

3. Neary D, Snowden JS, Gustafson L, Passant U, Stuss D, et al. (1998) Frontotemporal lobar degeneration: a consensus on clinical diagnostic criteria. Neurology 51(6): 1546-1554.

4. Verpillat P, Camuzat A, Hannequin D, Anterion TC, Puel M, et al. (2002) Association between the extended tau haplotype and frontotemporal dementia. Arch Neurol 59(6): 935-939.

5. Verpillat P, Camuzat A, Hannequin D, Anterion TC, Puel M, et al. (2002) Apolipoprotein E gene in frontotemporal dementia: an association study and meta-analysis. Eur J Hum Genet 10(7): 399-405.

6. The Lund and Manchester Groups (1994) Clinical and neuropathological criteria for frontotemporal dementia. J Neurol Neurosurg Psychiatry 57(4): 416-418.

7. Leucht S, Kane JM, Kissling W, Hamann J, Etschel E, et al. (2005) Clinical implications of brief psychiatric rating scale scores. Br J Psychiatry 187: 366-371.

8. David N, Julie S, David M (2005) Frontotemporal dementia. Lancet Neurol 4(11): 771-780.

9. Snowden JS, Neary D, Mann DMA (1996) Frontotemporal lobar degeneration: frontotemporal dementia, progressive aphasia, semantic dementia. Churchill Livingstone, UK.

10. Rosso SM, Donker KL, Baks T, Joosse M, Koning DI, et al. (2003) Frontotemporal dementia in The Netherlands: patient characteristics and prevalence estimates from a population-based study. Brain 126(Pt 9): 2016-2022. 